\title{
Oyun Bağımlılığı: Güncel Bir Gözden Geçirme
}

\author{
Game Addiction: A Current Review
}

\author{
Ayten Doğan Keskin ${ }^{1}$ (D), Neriman Aral ${ }^{2}$ (D) \\ 1. Sağlık Bilimleri Üniversitesi, Gülhane Sağık Bilimleri Fakültesi, Çocuk Gelişimi Bölümü, Ankara \\ 2. Ankara Üniversitesi, Sağlık Bilimleri Fakültesi, Çocuk Gelişimi Bölümü, Ankara
}

\begin{abstract}
Many digital games have emerged with the effect of technological developments in the 21st century. The overuse of these games has brought new diseases along. The most common of these diseases is game addiction. Game addiction is one of the behavioral addictions. Game addiction is defined by features such as being mentally busy with the game, thinking about the game, disrupting daily routines, continuing to play despite having negative consequences in academic, social and family life, reacting when playing is prevented, conflict, and exhibiting withdrawal symptoms. Studies on the definition, diagnosis, prognosis and treatment of this disease in our country are at the beginning level. However, along the Covid-19 pandemic, the time spent especially by children and adolescents for playing has increased, and children and adolescents have started to show signs of addiction. It is predicted that after the pandemic, applications to be made to health facilities related to game addiction will increase. For this reason, the study aimed to examine the definition, symptoms, prognosis, diagnostic criteria, prevalence, gender difference, play time, risk factors, effects on the individual and treatment of game addiction. The feature that distinguishes this study from other studies is that it includes a comprehensive explanation of game addiction and the information that forms the basis of the concept of game addiction. The topics discussed in this study are thought to be important, as they will form the basis of studies on game addiction and provide an understanding of the subject.
\end{abstract}

Keywords: Addiction, video games, diagnosis

Öz

21. yüzyıldaki teknolojik gelişmelerin etkisiyle birçok dijital oyun ortaya çıkmışır. Bu oyunların aşıı kullanımı ise yeni hastalıkları beraberinde getirmiştir. Bu hastalıklardan en yaygın olanı oyun bağımlıı̆̆ıdır. Oyun bağımlılı̆ı, davranışsal bağımlılıklardan biridir. Oyun bağımlılı̆ı, zihinsel olarak sürekli oyunla meşgul olma, oyunu düşünme, günlük rutin işlerini aksatma, akademik, sosyal ve aile hayatında olumsuzluklar yaşamasına rağmen oyun oynamaya devam etme, oyun oynama engellendiğinde tepki gösterme, çatışma, oyun oynayamadığında yoksunluk belirtileri sergileme gibi özelliklerle tanımlanır. Bu hastalı̆ın tanımlanması, tanılanması, seyri ve tedavisi ile ilgili ülkemizdeki çalısmalar başlangıç düzeyindedir. Buna rağmen, Covid-19 pandemisinde, özellikle çocuk ve ergenlerin oyun oynamaya ayırdığı zaman artmış ve çocuk ve ergenler bağımlıık belirtileri göstermeye başlamıştır. Pandemi sonrasında oyun bağımlılı̆ı ile ilgili sağlık tesislerine yapılacak başvuruların artacağı öngörülmektedir. Bu nedenle çalışmada, oyun bağımlıı̆ı̆ın tanımı, belirtileri, prognozu, tanı kriterleri, yaygınlı̆ı, cinsiyet farkı, oyun süresi, risk faktörleri, bireye etkileri ve tedavisi başlıklarının ele alınarak incelenmesi amaçlanmıştır. Bu çalışmayı diğer çalışmalardan ayıran özellik, oyun bağımlıı̆ının kapsamlı bir şekilde açıklanması ve oyun bağımlıı̆ı kavramının zeminini oluşturan bilgileri içermesidir. Bu çalışmada ele alınan başıklıarın, oyun bağımlılı̆ı ile ilgili yapılacak çalışmaların temelini oluşturacağı ve konunun anlaşılmasını sağlayacağı için önemli olduğu düşünülmektedir.

Anahtar kelimeler: Bağımlılık, video oyunları, tanı 


\section{Giriş}

Oyun insanoğlunun varlığından itibaren insanın hayatındadır. Oyun oynamak insanın en temel özelliklerindendir (1). Oyun çocuğun işidir, yetişkin içinse boş zamanı değerlendirme etkinliği ve eğlencedir. Oyun, oyuncuların yapay bir çatışma içine girdikleri, ölçülebilir bir kazanma durumuyla sonuçlanan kurallarla tanımlanan bir sistemdir (2).

Teknolojinin gelişmesiyle birlikte oyun kavramı daha da genişletilmiştir. Geçmişte oyun denilince bebek, araba gibi oyuncaklarla oyun oynama ile saklambaç, istop gibi oyunları oynama ilk olarak akıllara gelmekteydi. 1970'li yıllardan itibaren atariler ve atari salonlarının hayatımıza girmesiyle ekran üzerinden oynanan oyunlarla tanışılmıştır. Atari oyunlarılla birlikte avuç içi cihazlarla oynanan oyunlar da hayatımızda yer almıştır. Televizyonlara takılan oyun konsolları ile video oyunları, bilgisayarların gelişmesiyle birlikte de video oyunları ve bilgisayar oyunları oynanmaya başlanmıştır (3-5). Bilgisayarla birlikte internetin de kullanımaya başlamasıyla çevrimiçi ve çevrimdışı oyunlar yaygınlaşmıştır. Çevrimiçi oyunlar internet aracılığıyla oynanan oyunları, çevrimdışı oyunlar internet olmadan oynanan oyunları tanımlamaktadır. Teknoloji gelişmeye devam ettikçe akıllı telefon, tablet gibi ekranı olan cihazlarla da dijital oyunlar oynanmaya başlamıştır. Video oyunları ve bilgisayar oyunları terimleri sıklıkla birbiri yerine kullanılmaktadır. Video oyunlarında da bilgisayar oyunlarında da oyun ekranda görülmektedir. Video oyunları ile bilgisayar oyunları birbirinin yerine kullanılmasına rağmen video oyunları, bilgisayar oyunlarını kapsamakta ve video oyunları tablet, akıllı telefon, bilgisayar gibi cihazlarda oynanabilmektedir. Ancak bilgisayar oyunları sadece bilgisayarda oynanan oyunları içerdiği için tüm video oyunlarını kapsamamaktadır. Alanyazında bilgisayar oyunu ve video oyunu dışında dijital oyun terimi de kullanılmaktadır. Dijital oyunlar, video oyunları ve bilgisayar oyunları ekran aracılığı ile oynanan oyunlar olarak tanımlanmaktadır. Dijital oyun; kural, amaç, geri bildirim, zorluk, yarışma, zıtlık, meydan okuma, iletişim, etkileşim, sunum ve hikâye gibi ögeleri taşımaktadır (6). Oyun türleri; bireysel olarak oynanan dövüş oyunları, hem takım halinde hem bireysel olarak oynanan birinci/üçüncü kişi nişan/atış oyunları, gerçek zamanlı strateji oyunları, yarış ve spor oyunları, takım halinde oynanan devasa çok oyunculu çevrimiçi rol yapma oyunları ve bu kategorilere girmeyen-bahis ve kumar oyunları dışındaki- diğer oyunlar olmak üzere altı kategoriye ayrılmaktadır (7). Bu oyun türleri dışında meydan okuma (challenge) olarak tanımlanan, oyun olarak bilinen bazı uygulamalar oyun değildir. Kişiye çeşitli görevler vererek kişinin bu görevleri yapması beklenmekte, görevler yapılmadığında korku ve tehdit ögelerini içermekte olan uygulamalardır (8).

İnsanların oyun oynama alışkanlıklarının ve boş zaman etkinliklerinin zaman içerisinde değişmesiyle bazı problemler ortaya çıkmıştır. Bu problemlerden biri oyun bağımlılı̆ıdır. 1970'li yıllardan sonra ilk video oyunlarının hayatımıza girmesiyle bireylerin boş zaman etkinliklerinin yerini ekran üzerinden oynanan oyunlar doldurmuştur. Bu oyunlar günümüze kadar pek çok şekil değiştirmiş ve bugün bilgisayar, cep telefonu, televizyon, tablet, vs. gibi aletler başta olmak üzere birçok teknolojik aletle oyunlar oynanmaktadır. Teknolojik aletlerin çeşitlenmesi ve yaygın kullanımıyla birlikte oyuna erişim ve ulaşım kolaylaşmıştır. Dijital oyunlara erişim ve ulaşımın kolaylaşmasılyla bireylerin boş zamanı değerlendirme etkinlikleri ve oyun oynama alışkanlıkları da değişim göstermeye başlamıştır. Bazı bireyler ise gerçek dünya ile sanal dünya arasında denge kurmakta güçlükler yaşamış (9) ve bazı problemler ortaya çıkmaya başlamıştır. Bu problemler fiziksel ve psikolojik problemler olarak ele alınabilir. Fiziksel problemler; teknolojik aletlerin aşııı ve ergonomik olmayan kullanımlarıyla ortaya çıkan bel, baş, boyun, el, bilek ağrıları ve gözlerde yanma, batma, kaşınma gibi problemlerdir (8). Psikolojik problemler ise dijital oyunların bireyin hayatındaki en önemli etkinlik olması sonucunda diğer işlerine, hobilerine ilgisinin azalması ve onlara zaman ayırmaması; çeşitli duygularından uzaklaşma veya mutlu olma amacıyla oyun oynaması; oynadığı oyunun süresini her defasında artırması; oyun oynayamadığında yoksunluk çekmesi; oyun oynaması sınırlandırıldığında veya kesildiğinde çevresindekilerle çatışma yaşaması; oyun oynama davranışını kontrol altına alamaması; oyun oynama davranışını kontrol altına aldıktan bir süre sonra oyunu aşermesiyle tekrar oyun oynamaya başlamasıdır (10). Bu belirtiler bazı bireylerde oyun bağımlıı̆ının oluşmasına yol açabilmektedir. 
Oyun bağımlıı̆ını tanımlamadaki en büyük zorluk, patoloji ile aşııı oyun oynamayı birbirinden ayırt edememektedir (11). Bu sebeple dijital oyunlar ile ilgili psikopatolojinin incelenmesinde ve kategorilere ayrımasında, çevrimiçi oyun bağımlılığı kategorisinin oluşturulması desteklenmektedir. Çünkü bazı çevrimiçi oyunlar, bugüne kadarki en bağımlılık yapan internet etkinliklerinden biri olarak kabul edilmektedir (12-14).

Bu çalışma, dijital oyunların yeni hastalıkları beraberinde getirmesine odaklanmıştır. Bu hastalıklardan en yaygın olanı oyun bağımlıı̆ııdır (15). Bu hastalığın tanımlanması, tanılanması, seyri ve tedavisi ile ilgili ülkemizdeki çalışmalar başlangıç düzeyindedir. Bu nedenle çalışmada, oyun bağımlıı̆̆ının tanımı, belirtileri, prognozu, tanı kriterleri, yaygınlı̆ı, cinsiyet farkı, oyun süresi, risk faktörleri, nedenleri, bireye etkileri ve tedavisi başlıklarının ele alınarak incelenmesi amaçlanmıştır. Bu çalışmayı diğer çalışmalardan ayıran özellik, oyun bağımlılı̆ının kapsamlı bir şekilde açıklanması ve oyun bağımlılı̆ı kavramının zeminini oluşturan bilgileri içermesidir. Bu çalışmada ele alınan başılıların, oyun bağımlılığı ile ilgili yapılacak çalışmaların temelini oluşturacağı ve konunun anlaşılmasını sağlayacağı için önemli olduğu düşünülmektedir.

\section{Tanımı}

Oyun bağımlılığı davranışsal bağımlııklardan biridir. Davranışsal bağımlılıklar, madde ile ilişkili olmayan bağımlııklar olarak ele alınmaktadır. Davranışsal bağımlııklar; oyun bağımlılığı, internet bağımlı̆ğı, çevrimiçi alışveriş bağımlılı̆ı, pornografi bağımlıı̆̆ı, çevrimiçi kumar ve bahis bağımlılı̆ı, cep telefonu bağımlılığı olarak ele alınabilmektedir. Oyun bağımlıı̆ı, zihinsel olarak sürekli oyunla meşgul olma, oyunu düşünme, günlük rutin işlerini aksatma, akademik, sosyal ve aile hayatında olumsuzluklar yaşamasına rağmen oyun oynamaya devam etme, oyun oynama engellendiğinde tepki gösterme, çatışma, oyun oynayamadığında yoksunluk belirtileri gösterme şeklinde tanımlanabilmektedir (10).

Alanyazında teknoloji ile insan etkileşimi ile ilgili durumlar geçmişten günümüze farklı şekillerde tanımlanmıştır. Teknolojinin aşıı kullanımı kompulsif, problemli, patolojik ve bağımlı gibi terimlerle ifade edilerek, bu terimler birbirinin yerine kullanılmıştır (11). 1995 yılında Goldberg madde bağımlıı̆ı kriterlerini uyarlayarak "internet bağımlılı̆ı bozukluğu" terimini ilk kez dile getirmiş̧tir. İnternet bağımlılı̆ı bozukluğu için 12 aylık sürede, semptomlardan en az 3'ünün görülmesi gerektiğini belirtmiştir. Bu semptomlar; tolerans, yoksunluk, nüks etme, olumsuz sonuçlara rağmen kullanıma devam etme ve çevrimiçi olarak çok fazla vakit geçirmedir (16). Goldberg'in ardından K. Young (17) ve M.D. Grifftihs (18) internet bağımlıı̆̆ı ile ilgili alanyazında öncül çalışmalar ve olgu sunumları yapmışlardır (19). İnternet bağımlı̆̆ğ terimi çatısı altında problemli çevrimiçi faaliyetler yer almaktadır $(20,21)$. Bunlar; çevrimiçi alışveriş, sosyal medya kullanımı, çevrimiçi kumar, çevrimiçi oyun vd. Ancak internet bağımıı̆ığı çatısı altındaki bağımıııkların sınıflandırması ile ilgili altın bir standart şu an için bulunmamaktadır (19). İnternet bağımılı̆̆ı ile ilgili tanımlama ve tanılama gibi tartışmalar alanyazında hala devam ettiğinden, internet bağımlıı̆ı konusunun daha iyi anlaşılması için kültürler arası alanlarda yürütülen disiplinler arası araştırmalara gereksinim olduğu da belirtilmektedir (22).

Dünya Sağlık Örgütü oyun oynama bozukluğunu, Amerikan Psikiyatri Birliği de internet oyun oynama bozukluğunu tanımlamadan önce oyun bağımlılı̆ı farkı terimlerle tanımlanmaktaydı. Bu terimler; video oyunu bağımlıı̆̆ı, patolojik oyun oynama, oyun kullanım bağımlılı̆ı, oyun kullanım bozukluğudur $(23,24,25,26)$. İnternet oyun oynama bozukluğu tolerans, nüksetme, çatışma gibi yaygın bağımlıık bileşenlerini içermektedir (27). Internet oyun oynama bozukluğu ile oyun oynama bozukluğu terimleri birbirinden farklıdır. Oyun oynama bozukluğu hem çevrimiçi hem çevrimdışı oyunları ele alırken, internet oyun oynama bozukluğu internet aracilığılla sadece çevrimiçi oyunları ele almaktadır. Alanyazında bu terimlerin kullanımı ile ilgili de fikir birliği bulunmamaktadır. 


\section{Belirtileri ve Prognozu}

Davranışsal bağımlııklar, madde ile ilişkili bağımlııklardaki gibi belirtiler göstermektedir (28). Oyun bağımlılığının belirtileri; tolerans geliştirme, belirginlik, nüksetme, yoksunluk belirtileri sergileme, ruh hali değişikliği ve çatışmadır. Tolerans, bireyin oyun oynama veya oyunla ilgili etkinlerindeki harcadığı süreyi artırma gereksinimi duymasıdır. Belirginlik, oyunların bireyin hayatının merkezinde olması, düşüncelerinin, eylemlerinin oyunla meşgul olmasıdır. Nüksetme, bireyin oyun oynamasını kontrol altına aldıktan sonra davranışın tekrar ortaya çıkmasıdır. Yoksunluk belirtileri, bireyin oyun oynayamadığında veya aniden oyun oynaması azaltıldığında ortaya çıkan tepki ve duygulardır. Ruh hali değiş̧ikliği, oyun oynamayla ortaya çıkan heyecanlanma, rahatlama gibi ruhsal değişimlerdir (29). Çatışma, oyun oynama sonucunda ortaya çıkan işlevsellik kaybı, görevleri aksatma sonucu çevresi ile yaşadığı olumsuzluklardır (10).

Oyun bağımlısı oyuncularda görülen diğer belirtiler:

1. Hayatında oyunun öncelikli olması,

2. Oyunlarla veya oyun oynama süresi ilgili yalan söylemesi,

3. Oyun oynadığını çevresindekilerden gizlemesi,

4. Oyun oynamasına süre kısıtlaması getirilirse, kısıtlamalara karşı gelmesi,

5. Oyun dışındaki faaliyetlerine olan ilgisini kaybetmesi,

6. Çevresinden, ailesinden, öğretmenlerinden, arkadaşlarından uzaklaşması,

7. Oyunu bırakma çabalarında zorluk yaşaması,

8. Oyunu bir kaçış olarak kullanması,

9. Oyun oynadığı için çeşitli olumsuzluklar yaşaması ve buna rağmen oyun oynamaya devam etmesidir (30).

Bireyi oyun bağımlılığına götüren süreç net değildir. Çocuk ve ergenlerin ise oyun bağımlısı olması ile ilgili sınırlar çizmek, bağımlıı̆a giden yoldaki aşamaları belirlemek güçtür. Çünkü bir ergen uzun saatler oyun oynadığı halde bağımlıık belirtileri göstermediği gibi, başka bir ergen daha kısa süre oyun oynayıp bağımlılık belirtileri gösterebilir. Bu nedenle bireyin ne zaman bağımlı olduğunu belirlemek oldukça zordur. Hiçbir birey, oyun bağımlısı olmak için oyun oynamaya başlamaz, ancak bazıları bağımlı olabilir. Tüm bunlara rağmen ergenlerin bağımlılığa giden süreçte gösterdiği en belirgin belirti, oyun oynama süresini her defasında artırması ve oyuna karşı tolerans geliştirmesi ve yoksunluk semptomları sergilemesidir. Bireyin oyun oynadığı süre arttıkça, birey daha fazla oyunda kalarak, oyun oynayamadığında yoksunluk semptomları gösterebilmektedir. Bu nedenle bireylerde, özellikle çocuk ve ergenlerde, oyun oynama süresi ve sıkı̆̆ı oyun bağımlılığını yordamada önemli iki değişkendir (8).

İnternetin 7/24 kullanılabiliyor olması, her ortamda rahatlıkla internete ulaşılabilmesi, ödüllendirici, sürükleyici ve onaylayıcı olması internetin veya internetteki uygulamaların aşııı kullanılmasına yol açmakta ve bireyi bağımlılı̆a sürüklemektedir (31). İnternette bireyi bağımlılı̆a sürükleyen, oyunlardır. Bireyi bağımlılığa götüren en yaygın oyunlar ise çok oyunculu çevrimiçi rol yapma oyunlarıdır. Bilgisayar, cep telefonu, tablet gibi ekranlar üzerinden oynanan oyunlarda oyunun türü, süresi, yoğunluğu ve sıklığı oyun bağımlılığı belirtilerini ve oyun bağımlılığının prognozunu olumlu veya olumsuz olarak etkileyebilmektedir.

\section{Tanı Kriterleri}

Ruhsal Bozuklukların Tanısal ve Sayımsal El Kitabı'nın (Diagnostic and Statistical Manual of Mental Disorders [DSM]) beşinci baskısı olan DSM-5'te oyun bağımlıığı, "internet oyun oynama bozukluğu" olarak ele alınmış ve ileri araştırmalar yapııması önerilmiş̧tir. Söz konusu bozukluk için aşağıdaki tanı kriterlerinin 
12 aylık sürede, 5 veya daha fazlasının görülmüş olması ve tekrarlayıcı, sürekli kullanımının olması olarak belirlenmişstir (32).

DSM-5’te internet oyun oynama bozukluğu için tanı kriterleri:

1. İnternet oyunlarıla zihinsel olarak meşgul olmak.

2. İnternet oyunları olmadığında yoksunluk semptomları göstermek.

3. İnternet oyunlarına zaman geçtikçe daha fazla süre harcamak ve oyunlara karşı tolerans geliştirmek.

4. Oyun oynamayı kontrol etmede başarısızıklar yaşamak.

5. Oynadığı oyun süresi ile ilgili etrafındakilere doğruyu söylememek.

6. Daha önce ilgi duyduğu alanlara olan ilgisini kaybetmek.

7. Oyundan dolayı hayatında sorunlar yaşamasına rağmen oyuna devam etmek.

8. Oyunu kaçış ve rahatlama amacıyla kullanmak.

9. Oyun oynadığı için akademik hayatını, işini veya kariyerini tehlikeye atmak.

DSM-5’te tüm bu kriterler verilmiş olmasına rağmen, "internet oyun oynama bozukluğu" için "tam bir geçerlik kazanması için daha fazla araştırmaya gerek duyulmaktadır" açıklaması da bulunmaktadır (33).

Oyun bağımlılığı, sadece DSM-5'te değil, Hastalıkların Uluslararası Sınıflaması'nda da (International Classification of Diseases [ICD]-11), "bağımlılık yapıcı davranışların neden olduğu bozukluk çatısı altında", "oyun oynama bozukluğu" olarak ele alınmıştır. Oyun oynama bozukluğu, sürekli veya tekrarlayan (video, dijital vb.) oyun oynama davranışı ile kendini göstermektedir. Oyun oynama davranışı, sürekli ve tekrarlayıcıdır. Tanı için 12 aylık süre gözlem, değerlendirme veya takip gerekirken, belirtiler şiddetli bir şekilde kendini gösteriyorsa tanı süresi kısaltılmaktadır (34).

ICD-11'de oyun oynama bozukluğu için belirtilen tanı kriterleri:

1. Oyun ile ilgili başlangıç, sıklık, yoğunluk, süre, sonlandırma ve günlük aktivite gibi konularda kontrol sağlayamaması.

2. Oyuna öncelik vermeyi arttırması ve günlük faaliyetler yerine oyunun öncelik alması.

3. Sosyal çevresiyle yaşadığı olumsuzluklara rağmen oyuna devam etmesi.

Oyun bağımlıı̆ı, internet bağımlılığı ve söz konusu tanı kriterlerinde geçen bozukluklar araştırmacılar tarafından birbirlerinin yerine kullanılmaktadır. Ancak bu kavramların bazısı diğerini kapsamakla birlikte, tamamını açıklamada yetersiz kalabilmektedir. Oyun oynama bozukluğu ile internet oyun oynama bozukluğu birbirinden farkı olduğu için tanılanması da farklı olmalıdır (35). Örneğin; internet oyun oynama bozukluğu sadece çevrimiçi oyunları kapsarken, oyun oynama bozukluğu hem çevrimiçi hem çevrimdışı oyunları kapsamaktadır. Dolayısıyla oyun oynama bozukluğu, internet oyun oynama bozukluğunu kapsamaktadır. Tüm bunlara rağmen oyunların kapsamı ile ilgili alanyazında yapılan çalışmalar fikir birliğinin sağlanmadığını da göstermektedir. Oyun bağımlıı̆̆ı ile ilgili tanılamada fikir birliği olmadığı için mevcut durumu belirlemede de, uygun ölçme araçlarını veya yöntemleri kullanmak gerekmektedir. Alanyazında oyun bağımlıı̆̆ını değerlendirmek için internet bağımlılığını değerlendiren araçlar kullanılmaktadır. Ancak ölçülmek istenen oyun bağımlıığı düzeyi iken, internet bağımlılığı ölçekleriyle bireylerin internet bağımlılık düzeyleri ölçülmektedir (36). Oyun bağımlılığını değerlendirmek için oyun bağımlıı̆ı ölçekleri, internet bağımlığını değerlendirmek için internet bağımlılı̆̆ı ölçekleri kullanılmalıdır. Söz konusu bağımlılıklarda spesifik değerlendirmeler, değerlendirmek istenene yönelik geliştirilmiş olan ölçme araçlarını kullanmak önemli ve gereklidir. Bu sebeple öncelikle standardizasyonu yapılmış ölçme ve değerlendirme araçlarıyla bağımlı̆̆ğn belirlenmesi gerekmektedir. Bağımlılık durumu belirlenirken de ölçülmek istenen davranışsal bağımlılıklardan hangisi ise (oyun, internet, çevrimiçi alışveriş, sosyal medya, çevrimiçi kumar vb.) ona uygun ölçme ve değerlendirme aracını kullanmak, durumun değerlendirilmesi ve 
belirlenmesinde doğru sonuçlara ulaşılmasını sağlayacaktır. Böylece problem durumunun tespiti doğru bir şekilde yapılacak ve yaygınlık, müdahale, tedavi gibi adımların da doğru atılmasını sağlayacaktır.

\section{Yaygınlığı}

Bir hastalığın bir toplumda görülme sıklığını yani yaygınlığını belirlemek, yaygınlığa göre müdahale stratejileri ve politikalar belirlemeye imkân tanır. Yaygınlık belirlenirken genel popülasyondaki yaygınlık ile klinik örneklemdeki yaygınlık oranları birbirinden farklı olabilmektedir. Oyun bağımlılığıyla ilgili yapılan yaygınlık çalışmalarında da yaygınlığın ülkeden ülkeye göre farklııklar gösterdiği belirlenmiştir. Bu farklılı̆ın birçok sebebi olmakla birlikte; kültürel özelliklerden, araştırmalarda kullanılan metodolojiden ve ölçme araçlarından kaynaklandığı tahmin edilmektedir (19). Dünyada oyun bağımlıığının yaygınlığı \%0,6 ile \%15 arasında değişmektedir (37). Avrupa'da İnternet bağımlılı̆ı yaygınlığı \%4,2 olarak belirlenmiştir (38). Dünyada Doğu Asya ülkeleri oyun bağımlılığının en yaygın olduğu yerlerdir ve oyun bağımlılığı bu ülkelerde halk sağlığı sorunudur (19).

Amerikan Psikiyatri Birliği'ne göre Internet oyun oynama bozukluğu yaygınlığının Asya ülkelerinde ve 12-20 yaş arası erkek ergenlerde yüksek olduğu tahmin edilmektedir. Asya'da yapılan bir çalışmada 15-19 yaş arasındaki ergenlerde yaygınlık oranı erkekler için \%8,4 ve kadınlar için \%4,5’tir (32).

Çin'de genç erişkinlerde çevrimiçi oyun bağımlıı̆̆ı yaygınlığı 2005 yılında \%5,4 iken, 2008 yılında bu oran \%11,6'ya yükselmiştir $(39,40)$. Singapur'da ilk ve ortaokul popülasyonunda yapılan boylamsal bir çalışmada, patolojik oyun oynama yaygınlığı yaklaşık \%9 ve yapılan bir diğer meta-analiz çalışmasında ise yaygınlık oranı \%3,1 olarak bulunmuştur $(41,42)$. Ergenlerde bilgisayar oyun bağımlılı̆ı yaygınlığı oranı $\% 0,9$ ile \%1,7 arasında değişmektedir (43). Dünyaya 2019 yllında yayılan Covid-19 salgını yüzünden, insanlar karantinaya girip evlerine kapanmıştır. Bunun sonucunda ise çocuk ve ergenlerin internet kullanımı geçen yıllara göre \%500 artmıştır (44). Ayrıca çevrimiçi oyunlar ile ilgili aramalar, salgın döneminin belli aylarında 20 kata varan artışlar göstermiştir (45).

Dünyada her üç internet kullanıcısından birinin, çocuk veya ergen olduğu tahmin edilmektedir (46). Türkiye'de de çocuklar interneti, erken çocukluk döneminde kullanmaya başlamaktadır (47). Buna karşın dünyadaki gençlerin sadece \%29'u internet kullanamazken; Avrupa'da bu oran \%4, Afrika'da \%60'dır (46). Dolayısıyla farklı ülkelerde internet aracılığıyla oynanabilen oyunlar ve sonrasında gelişebilen oyun bağımlıı̆ı oranları da farklıık göstermektedir. Oyun bağımlılı̆ı Çin, Japonya, Kore, Tayvan ve Amerika gibi ülkelerde yaygınken Avrupa'nın bazı ülkelerinde ve Afrika'da yaygın değildir $(38,46)$. Oyun bağımlıığının yaygınlık oranları ülkeden ülkeye farklılık göstermesine rağmen kabul edilmesi gereken, dünyanın birçok ülkesinde oyun bağımlıı̆ı, davranışsal bağımlılıklardan biridir. Bu bağımlıık birçok ülkede yaygındır ve gelecekte bu tablonun ve bağımlıı̆ın uzun vadede seyri henüz belirsizdir.

\section{Oyun Bağımlılığında Cinsiyet Farkı}

Normal gelişim gösteren veya göstermeyen kız veya erkek tüm bireyler oyun bağımlılı̆ına duyarlı olabilirler, fakat erkek ergenlerde görülme sıklığı diğerlerine göre daha fazladır. Ayrıca, bilgisayar oyunları 12-25 yaş arası erkekler arasında en popüler eğlence aracıdır. Oyun bağımlılığı konusunda ergenler yetişkinlere göre daha savunmasızdır (48).

Bilgisayar oyunlarının büyük çoğunluğu, temel olarak erkek oyuncu pazarı için hazırlanmıştır. Bu durumun, kızların kendi yaşıı olan erkeklerden daha fazla akademik olma eğiliminde olmalarından ve bu yüzden bilgisayar oyunu oynayarak derslerini inmal etmeyi istememelerinden kaynaklandığı da ileri sürülmektedir. Ayrıca bireylerin oyun davranışlarının sinirsel süreçleri ile ilgili bilgive erişmek için fonksiyonel manyetik rezonans görüntülemeleri incelenmiştir. Sonuçlara göre erkeklerde kadınlara kıyasla mezokortikolimbik sistemde daha fazla aktivasyon ve fonksiyonel bağlantı gözlendiği için erkeklerin kadınlara göre oyunlara bağımlı olma olasılıklarının daha fazla olduğu belirlenmiştir (49). Cinsiyetler arasında oyun bağımlılı̆ı yaygınlığını etkileyen faktörler, çevresel ve biyolojik olarak ele alınmış ve oyun bağımlıı̆̆ının erkeklerde 
kızlara göre daha yaygın olduğu belirlenmiştir. Ancak mevcut durumda kızların bağımlı olmadığı veya olmayacağı anlamına gelmemekle birlikte, ileri araştırmalarda biyolojik cinsiyetten bağımsız olarak kıza ve erkeğe ait özelliklerden hangilerinin oyun bağımlılı̆ında daha belirleyici olduğu da incelenmelidir.

\section{Oyun Oynama Süresi}

Araştırmalar, erkek ergenlerin zamanlarının çoğunu ve giderek artan miktarlarda dijital oyun oynayarak geçirdiğini göstermektedir (50). Dijital oyunlar özellikle erkeklerin daha fazla dikkatini çekmektedir. Bunun sebebi, dijital oyunlarını tasarlayanların çoğunun erkek olmasından kaynaklanabilir (10). Cinsiyete göre oyun oynama süreleri değerlendirildiğinde, erkeklerin haftada ortalama 13 saat, kadınların ise haftada ortalama 5 saat oyun oynadığı belirtilmektedir (50). Yapılan bir çalışmaya göre, bir ergenin 21 yaşına kadar ortalama 10 bin saatini oyun oynayarak geçirebileceği öngörülmektedir (51). Bunun yanı sıra oyun oynayan oyuncular, oyun oynama dışında oyun ile ilgili bilgilerin bulunduğu, canlı yayınların yapıldığı, canlı yayınlarda oyunların oynandığı çeşitli platformlarda da oldukça fazla vakit geçirmektedir. Bazı oyuncular tarafından ise oyun oynayanın canlı yayında yayınladığı oyununu izlemek, oyun oynamaktan daha heyecan verici bulunmaktadır (8). Oyun bağımlılı̆ında oyun oynama süresi cinsiyete göre değişmektedir. Oyun bağımılı̆ğında oyun oynama süresi dikkate alınmalıdır, ancak süre bağımlılık için tek bir belirleyici faktör değildir. Her gün 2 saat oyun oynayan bir birey bağımlı olurken, bir başka birey her gün 2 saat oyun oynayıp bağımlı olmayabilir. Oyun bağımlıı̆ında birey oyun oynamasa da sürekli oyunu düşünüp, oyunla ilgili çeşitli videolar izliyorsa bu durum, oyun bağımlılığına giden yolda ele alınmalıdır. Başkası tarafından oynanan oyunu izleme süresi, oyun bağımlılığının değerlendirilmesinde bir değişken olarak ele alınabilir. Çünkü birey oyun oynamasa da oyunla meşguldür ve oyunu düşünüyordur.

\section{Risk Faktörleri}

Oyun bağımlılığının risk ve seyri ile ilgili faktörler çevresel ve genetik ve psikolojik olmak üzere iki başlık altında toplanmaktadır. Çevresel faktörler, internet bağlantıı bilgisayarın farklı oyunlara erişim sağlaması nedeniyle Internet oyun oynama bozukluğu ile ilişkilidir. Genetik ve psikolojik faktörde ise erkek ergenlerin Internet oyun oynama bozukluğunun gelişiminin ortaya çıkmasında büyük risk grubunda oldukları görülmektedir (32).

Bilgisayar oyunları tek seferlik bir deneyim sunmaz, defalarca deneyimlenebildiği için etki gücünün daha da arttığı varsayılmaktadır. Aşııı oyun oynamadan dolayı birey sağıı̆ını inmal edilebilir. Ayrıca oyun oynama ve oyunun kendisiyle ilgili oyuna fazla anlam yükleme, oyun ödüllerine fazla odaklanma gibi olumsuz bilişlere sahip bireyler depresyon ve kaygı gibi duygudurum belirtileri sergileyebilmektedir (52). Oyun bağımlılı̆ı depresyon, DEHB, yalnızlık, anksiyete bozukluğu gibi psikopatolojik semptomlar, çeşitli mental bozukluklar ve kişilik özellikleriyle ilişkilendirilmiştir (53). Farklı kişilik özelliklerine sahip olma da problemli internet kullanımı ve çevrimiçi oyunlarla ilişkilidir (54).

Ekran üzerinden oynanan oyunlar, bireylerin oyuna/ ekrana odaklanmalarını sağladığı için oyuna başlama, oyun oynama sıklığı, yoğunluğu ve süresi, oyunu sonlandırma gibi konularda kontrol kaybı yaşamaları olasıdır (55). Bu bireyler dünyadan kendilerini uzaklaştırarak, oyuna odaklanmaktadır. Buna rağmen oyun bağımlılığı, özellikle dikkat ile ilgili problemi olan DEHB tanılı çocuklarda daha yaygındır (56). Oyun bağımlıı̆ında bireyin kendisine ve çevresine bağlı risk faktörleri etkili olmaktadır. Bu risk faktörleri oyun bağımlıı̆ı̆ın seyrini olumsuz bir şekilde etkileyebilmektedir.

\section{Nedenleri}

Oyun bağımlılı̆ının nedenleri karmaşıktır (57). Tek bir veya birden fazla neden oyun bağımlılı̆ını tetikleyip bağımılı̆ğın meydana gelmesine sebep olabilir. Oyun bağımlılığının nedenleri içsel faktörler ve dışsal faktörler olarak iki alt grupta ele alınmaktadır (29). İçsel faktörler; düşük benlik saygısı, öz düzenleme sorunları, oyun oynama motivasyonu, yapısal ve fonksiyonel nörobiyolojik anormallikler, depresyon, DEHB, 
sosyal fobi gibi komorbid hastalıklardır. Dışsal faktörler; ebeveyn sorunları, olumsuz rol modeller, inmal, aile içi şiddet gibi ailesel faktörler, ilişki sorunları ve sosyal izolasyon gibi sosyal faktörler ve oyunun kendisine ait faktörlerdir (58). Bu faktörler dışında henüz belirlenmiş faktörler ve risk grubundaki bireyler için tetikleyici faktörler de oyun bağımlılığının oluşmasına yol açabilir.

\section{Bireye Etkileri}

Oyun oynamak, eğlence ve boş zamanı değerlendirme etkinliği olabileceği gibi bireyin hayatındaki tek odağı veya işi de olabilmektedir. Oyun oynamanın bireye olumlu ve olumsuz bazı etkileri olabilmektedir. Olumsuz etkilerin bazıları çocuk ve ergenler tarafından olumlu; olumlu etkilerin bazıları ise yetişkinler tarafından olumsuz olarak kabul edilebilmektedir. Örneğin, oyun oynama bireyin rahatlamasını ve keyifli vakit geçirmesini sağlar. Ergenler tarafından bu durum olumlu olarak değerlendirilirken, yetişkinler bu zamanı boşa geçen zaman olarak ele alıp olumsuz bir şekilde değerlendirebilmektedir. Uzun saatler bilgisayar başından kalkmayarak oyununu tamamlamak isteyen ergen uykusuz kalabilir. Ergen uykusuz kalmayı göze alarak, oyununu tamamlamıştır ve bu durum onun için olumlu bir sonuçtur. Ancak yetişkin için ergenin uykusuz kalması olumsuz bir durumdur. Oyun oynamanın olumlu ve olumsuz etkileri aşağıda sıralanmıştır:

\section{Olumlu Etkileri}

Oyunlar eğlence amacıyla kullanılabildiği gibi tedavi, ağıı ve acıyı azaltma amacıyla ve eğitim amacıyla da kullanılabilmektedir. İyi tasarlanmış oyunlardan bazıları, el-göz koordinasyonu ve görsel-uzamsal beceriyi geliştirmekte, yer-yön konusunda yeni şemalar kazandırmakta, çeşitli sağlık sorunlarıla baş etmeyi sağlamakta ve tedavi amacıyla kullanılmaktadır $(59,60,61)$. Dijital oyun türleri, tek bir alanda tek bir beceri gelişimini hedeflemez ve bir oyun birden fazla beceri alanını etkileyebilmektedir. Dijital oyunlar; bölünmüş dikkat isteyen görevleri daha hızlı ve doğru şekilde yapma becerisini kazandıır, simülasyonların daha kolay anlaşılmasını sağlar, 3 boyutlu bilgilerin yani görsel-uzamsal ögelerin okunması ve yorumlanması becerisini kazandırır (62), aktif öğrenme ortamı sunduğu için sosyal ve iletişim becerilerinin gelişimini destekler, tüm bu becerilerin kazanımını desteklediği için eğitsel ve bilişsel becerilerin de gelişimini sağlar. Bunların yanı sıra sağlıkla ilgili yaşanan problemlerin sağaltımında kullanılabilir. Örneğin; Amerika'da pediatrik hastaların acılarını ve kaygılarını hafifletmek için ortopedi, görüntüleme, cerrahi, perioperatif bakımda sanal gerçeklik gözlükleri kullanılmaktadır (63). Diyabetli çocuklar için "kendi kendine bakım" ile ilgili bilgi ve beceri kazanmasına yönelik tasarlanan oyunların diyabetli çocuklarda kullanılması, çocukların hastalı̆ı̆ ile ilgili insülin enjeksiyonu gibi sağlık uygulamalarını yapabilmesini sağlayabilmektedir (64). Sağlık sektöründe oyunların kullanılması, oyun sektörünün gelecekte ilaç sektörüyle yarışabileceğini göstermektedir (8).

\section{Olumsuz Etkileri}

Eğlence amacıyla oynanan oyun bireyi rahatlatabilmektedir ancak, kontrol kaybedildiğinde riskleri beraberinde getirebilmektedir. Ergenlerde oyun bağımlıı̆̆ okul başarısızı̆̆ı, kız arkadaştan/erkek arkadaştan ayrılma, bursu kaybetme, basit hijyen gereksinimlerini aksatma gibi sonuçlara yol açabilir. Yetişkinler ise işlerini kaybedebilmektedir. Bunun yanında aile sorumluluklarını inmal edip, aile ilişkilerini ve evliliklerini yitirmekte olsalar bile oyunlarına sadık kalmakta ve oyun oynamaya devam edebilmektedirler (30). Çevrimiçi oyun oynayan oyuncuların bazısı kendilerini oyuna kaptırarak okullarını bırakabilmekte, işlerinden çıkabilmekte, arkadaş ve aileleri arasına mesafe koyarak onlardan uzaklaşabilmektedir $(30,48)$.

Uzun süre ekran başında kalma, kas-iskelet sorunlarına ve öksürük kapasitesinin azalmasına ve sonucunda solunumla ilgili komplikasyonların oluşmasına yol açabilmektedir (65). Bunun dışında çeşitli fiziksel problemlere, bel-boyun-baş-bilek-el ağrılarına, görme ve işitme ile ilgili sorunlara, aile ve arkadaşlarla sorunlar yaşanmasına, akademik başarının düşmesine ve en önemlisi kişinin bağımlı hale gelmesine yol açabilmektedir.

Ekran üzerinden oyun oynayan oyuncular, oyun becerilerini geliştirmek ve oyunda kalma sürelerini artırmak için çeşitli deneme ve çalışmalar yapmaktadır. Aralıksız oyun oynamaya devam edebilmek için bazı gereksinimlerini farklı şekillerde karşılayabilmektedir. Örneğin, oyun kapasitesini artırmaya çalışan bir genç, 
kullandığı teknolojik cihazı naylonla kaplayıp duşa o şekilde girmektedir (66). Ekran başında oyun oynayıp, çevrimiçi oyundan ayrımadığı için ebeveynleri tarafından beslenen ergenler de bulunmaktadır. Bazı ergenler ise kaşıkla-çatalla yenilebilecek yemekler yerine, pipetle içilip elle yenilebilen yiyecekleri, fast food tarzı yemekleri tercih edebilmektedir (67). Bu durumlar, bireyin sağıklı yaşam biçimi davranışlarını inmal ettiğinin kanıtıdır. Sağlıkı yaşam biçimi davranışı sadece özbakım ve beslenme ile ilgili değildir, uyku da sağlıklı yaşam biçimi göstergelerinden biridir. Ergenler daha fazla oyun oynamak için uykusuz kalabilmektedir. Uzun süre uykusuzluk ise DEHB belirtilerine benzer belirtilerle kendini göstermektedir. Oyun nedeniyle uykusuzluk yaşayan ergenlerin bir kısmının da DEHB olduğu düşünülmektedir (66). Ancak bu ergenlerden bazıları DEHB değil, sadece oyun bağımlısıdır.

Ergenler için arkadaş çevresi ve ergenlerin arkadaşlarılla ilişkisi oldukça önemlidir. Güçlü arkadaşlıklar, oyun bağımlılarının psikososyal sorunlarını önlemektedir (68). Ancak ergenler, oyunları arkadaşlarından öğrenip, onların kendisini kabul etmesi için de oyun oynamaya başlayabilmektedir. Geçmişte ergenler, arkadaşları arasında aile, öğretmen, karşı cins, müzik, spor gibi konularda konuşmalar yaparken, günümüzdeki ergenler sosyal medya, oynadıkları oyunlar, kullandıkları veya sahip oldukları teknolojik aletlerle ilgili konularda konuşmalar yapabilmektedir. Dolayısıyla çocuğun veya ergenin çevresinde oyunla erken tanışan, erken yaşta akıllı telefon, tablet veya bilgisayar vb. alet sahibi olanlar, çocuk veya ergenin de bu aletlerle, dolayısıyla uygulamalarla ve oyunlarla tanışmasına yol açabilir.

\section{Tedavisi}

Oyun bağımlılı̆ının tedavisinden önce yapılması gereken, çocuk ve ergenin bağımlı olmasını önlemektedir. Önleme, tedaviden daha güçlü ve pratik bir yoldur. Bu nedenle ebeveynlerin çocuklarını dikkatli bir şekilde gözlemlemesi, normalden farklı durumlar geliştiğinde, zaman kaybetmeden yardım arayışlarına girmesi, çocuğunun uzun soluklu tedaviler almasını engelleyip çocuğunun bağımlı olmasını önleyebilir. Oyun bağımlılığını önlemede; öz düzenleme yaklaşımı, oyunun türüne ve süresine kısıtlama getirmeye yönelik psiko-eğitimler, sosyal beceri eğitimleri, sosyal ve sportif etkinlikleri içeren alternatif etkinliklere yönlendirme kullanılabilmektedir (58).

Oyun bağımlıığının tedavilerinin etkinliğini değerlendiren çok az çalışma vardır. Oyun bağımlıı̆̆ının tedavisinde i) farmakolojik tedavi, ii) farmakolojik olmayan tedavi ve iii) kombine yani farmakolojik tedavi ile birlikte uygulanan farmakolojik olmayan tedavi yaklaşımları kullanılmaktadır. Kombine müdahaleler tek bir müdahaleye göre daha etkili sonuçlar vermektedir (69).

Farmakolojik tedavide, belirli sürelerle çeşitli ilaçlar kullanılmaktadır. Yapılan bir çalışmaya göre oyun bağımlısı olan 11 hastaya uygulanan 6 haftalık bupropion tedavisi sonucunda yapılan değerlendirmede, oyun bağımlılarının oyun oynama sürelerinin azaldığı belirlenmiştir (70). Yapılan bir diğer çalışmada çevrimiçi oyun bağımılı̆ğının şiddeti ile depresif belirtilerin azaltılması hedeflenerek, bu iki problemi yaşayan 50 erkek hastaya bupropion tedavisi 12 hafta süreyle uygulanmıştır. Tedavi sonucunda yapılan değerlendirmede, hastaların depresif ruh hallerinde ivileşme ve oyun bağımlıı̆̆ şiddetinde azalma olduğu belirlenmiştir (71). Bu çalışmalar prospektif ve kontrol gruplu çalışmalar olarak tasarlanmıştır. Bupropion dışında antidepresanlar ve DEHB tedavisinde kullanılan metilfenidat gibi çeşitli ilaçların 6-12 haftalık kullanımlarının oyun bağımlıı̆̆ belirtilerini azaltmada etkili olduğu sonucuna ulaşıımıştır (72).

Oyun bağımlı̆̆̆ıın farmakolojik olmayan tedavisinde, bilişsel davranışçı terapi (BDT) sıklıkla kullanımaktadır. Oyun bağımlılı̆ında baskın olarak kullanılan BDT stratejisi, kontrollü bir davranış planıdır (57). Oyun bağımlılığının tedavisinde kullanılan BDT yaklaşımları; yoksunluk semptomlarından aşermeye odaklanan BDT, farkındalık temelli BDT, oyuna odaklanan BDT ve standart BDT'dir (72). Standart BDT oyun bağımlıı̆ının tedavisinde etkili sonuçlara ulaşılmasını sağlamaktadır. Standart BDT'de sadece oyun bağımılı̆̆ına odaklanılmaktadır. Tedavinin odağını değiştirip oyun bağımlıığı, komorbid belirtiler, psikososyal etkenler gibi değişkenlerle ele alınıp bütüncül yaklaşıldığında ergenlerde davranış değişikliğini sağlama daha etkili olabilmektedir (73). Yapılan bir çalışmada oyun bağımlısı 13-18 yaş arası ergenler için standart BDT yaklaşımı benimsenerek bir psikoterapi programı hazırlanmıştır. Haftada 1 seanstan oluşmak 
üzere ergenlere uygulanan 6 aylık bir psikoterapi programının sonunda ergenler değerlendirildiğinde, psikoterapi programının oyun oynama süresinde azalma, oyun bağımlılı̆ı semptomlarında iyileşme ve komorbid bozukluklardan daha düşük puanlar almada etkili olduğu belirlenmiş̧tir (74). BDT oyun bağımlılığında etkili bir tedavi yaklaşımı olarak kabul edilmesine rağmen, oyun bağımlıı̆ı̆ının altında yatan bilişler karmaşıktır (57). Oyun bağımlılığının tedavisinde BDT kullanan çalışmaların biliş temelli ölçümlerden yoksun olması (57) ve yüksek kaliteli randomize kontrollü araştırmaların yetersiz olması (58) bir eksiklik olarak değerlendirilebilir.

Oyun bağımlıları ve oyun oynama süresini azaltmaya çalışanlarla yoksunluk yönetimi çalışmaları ve psikoeğitim müdahaleleri yapılabilmektedir (52). Teknoloji tabanlı tüm bağımlılıklarının tedavisinde bilişsel davranışçı terapi, çeşitli terapötik yaklaşımlar, çözüm odaklı terapi ve kişilerarası terapi kullanılabilmektedir (35). Güney Kore'de oyun bağımlısı olan çocukların \%24'ü sağlık tesislerinde yatarak; Japonya'da ise rehabilitasyon merkezlerinde tedavi edilebilmektedirler (33). Türkiye'de ise oyun bağımlılı̆ı tanısı da dâhil olmak üzere, sağlık kurumlarının internet bağımlıığı polikliniklerinde, psikiyatri kliniklerinde tedavileri yapılabilmektedir.

\section{Sonuç ve Öneriler}

Oyun bağımlıı̆ı; dünyadaki birçok ülke tarafından yakından takip edilen, Covid-19 salgınıyla birlikte çevrimiçi oyun kullanımının artmasıyla ailelerin endişe duyduğu, günümüzde tanıma-tanımlama-ayırt etme çalışmaları başta olmak üzere, sağalıım çalışmalarına odaklanılan, koruyucu çalışmalar kapsamında farklı projeler yürütülen halk sağlığı sorundur. Sorunun ciddiyeti ile ilgili çeşitli belgeseller çekilmiş, oyun bağımlıarına ve ailelerine yönelik rehber kitaplar hazırlanmıştır. Ülkemizde de bu konuyla ilgili çalışmalar, büyük örneklemlerle üzerinde kapsamlı ve hızlı bir şekilde yapılmakta, çeşitli kurumlar aracilığılla çocuk, ergen ve ailelere eğitimler verilmekte, bu alanda çalışacak uzmanlara Sağlık Bakanlığı tarafından eğitimler verilmektedir.

Oyun bağımlıı̆ı, madde ile ilgili bağımlııklar kadar tehlikeli ve tedavi gerektirmektedir. Bu bağımlıı̆̆ diğerlerinden ayıran en önemli özelliği, çocuk ve ergenleri dahi etkileyip, ailesiyle yaşadığı çatı altında, evin içerisinde, ailenin yanında çocuk veya ergenin bağımlı olabilmesidir. Bilgisayar başında oyun oynayan oyuncuda sessiz bir şekilde ilerleyen bu sorun, sadece bireyi değil, çevresini ve toplumu da ilgilendirmektedir. Bu nedenle oyun bağımlıı̆ı konusunda koruyucu ve önleyici çalışmalara ve farkındalık çalışmalarına gereksinim bulunmaktadır. Özellikle çocuk ve ergenleri oyun bağımlılı̆ından korumaya yönelik eğitim programlarının oluşturulması ve oyun bağımlılı̆ına yönelik tedavi, destek ve izlem merkezlerinin açılması önerilmektedir.

\section{Teşekkür}

Bu yazı Prof. Dr. Neriman Aral danışmanlı̆ında yürütülen, Dr. Öğr. Üyesi Ayten Doğan Keskin tarafından hazırlanan doktora tezinden üretilmiş̧ir. Bu yazının yararlandığı tez çalışması, Yeşilay Lisansüstü Tez Araştırma Bursuyla 2017/5 döneminde desteklenmiştir.

\section{Kaynaklar}

1. Huizinga J. Homo Ludens: Oyunun Toplumsal İslevi Üzerine Bir Deneme. İstanbul: Ayrıntı Yayınları, 1995.

2. Salen K, Zimmerman E. Rules of Play: Game Design Fundamentals. Massachusetts: MIT Press, 2004.

3. Kukul V. Oyunla ilgili tarihsel gelişim ve yaklaşımlar. Ocak MA (Editör). Eğitsel Dijital Oyunlar. Ankara: Pegem Akademi, 2013; 20-31.

4. Demir K, Şahin YL. Çocuklar ve dijital oyunlar. Odabaşı F (Editör). Dijital Yaşamda Çocuk. Ankara: Pegem Akademi, 2017; 177-192.

5. Miller M. A history of home video game consoles Available from http://www.informit.com/articles/article.aspx?p=378141. Accessed 31.03.2021.

6. Prensky M. Digital Game-Based Learning. New York: McGraw-Hill, 2001. 
7. Bayrak G. Dijital Oyunlar Için Çocuk ve Aile Rehberliği Çalıştayı Sonuç Raporu. Ankara: Aile ve Sosyal Politklar Bakanlığı, 2017.

8. Doğan-Keskin A. Oyun bağımlılı̆ı müdahale programının ergenlerin oyun bağımlılığı ve oyun motivasyonu ile duygusal davranışsal sorunlarına ve annelerinin düşüncelerine etkisinin incelenmesi. Doktora Tezi, Ankara: Ankara Üniversitesi Sağık Bilimleri Enstitüsü, Çocuk Gelişimi ABD, 2019.

9. Ögel K. İnternet Bağımlılığı. İstanbul: Iş Bankası Yayınları, 2011.

10. Griffiths MD. Diagnosis and management of video game addiction. Direct Addict Treat Prevent 2008; 12: $27-$ 41.

11. Moge CE, Romano DM. Contextualising video game engagement and addiction in mental health: The mediating roles of coping and social support. Heliyon 2020; 6(11): e05340.

12. Kuss DJ, Louws J, Wiers RW. Online gaming addiction? Motives predict addictive play behavior in massively multiplayer online role-playing games. Cyberpsychol Behav Soc Netw 2012; 15(9): 480-485.

13. Kuss DJ, Griffiths MD. Online gaming addiction in children and adolescents: A review of empirical research. J Behav Addict 2012; 1(1): 3-22.

14. Kuss DJ, Pontes HM, Király O, et al. A psychological overview of gaming disorder. Attrill-Smith A, Fullwood C, Keep M, Kuss DJ (Editors). The Oxford Handbook of Cyberpsychology. Oxford: Oxford University Press, 2019.

15. Rajab AM, Zaghloul MS, Enabi S, et al. Gaming addiction and perceived stress among Saudi adolescents. Addict Behav Rep 2020; 11: 100261.

16. Goldberg I. Internet addiction disorder (IAD) diagnostic criteria. http://www. psycom. net/iadcriteria. html (Accessed 31.03.2021)

17. Young KS. Addictive use of the Internet: A case that breaks the stereotype. Psychol Rep 1996; 79: 899-902.

18. Griffiths MD. Internet addiction: An issue for clinical psychology? Clinical Psychology Forum 1996; 97: 32-36.

19. Kuss DJ, Griffiths MD, Karila L, et al. Internet addiction: A systematic review of epidemiological research for the last decade. Curr Pharm Des 2014; 20(25): 4026-4052.

20. Adams BLM, Stavropoulos V, Burleigh TL, et al. Internet gaming disorder behaviors in emergent adulthood: A pilot study examining the interplay between anxiety and family cohesion. Int J Ment Health Addict 2018;17: 828-44.

21. Burleigh TL, Griffiths MD, Sumich A, et al. A systematic review of the co-occurrence of Gaming Disorder and other potentially addictive behaviors. Curr Addict Rep 2019; 6(4): 383-401.

22. Duong XL, Liaw SY, Augustin JL. How has internet addiction been tracked over the last decade? A Literature review and 3C paradigm for future research. Int J Prev Med 2020; 11: 175.

23. Estévez A, Jáuregui $P$, Sánchez-Marcos I, et al. Attachment and emotion regulation in substance addictions and behavioral addictions. J Behav Addict 2017; 6(4): 534-544.

24. Lemmens JS, Valkenburg PM, Peter J. The effects of pathological gaming on aggressive behavior. J Youth Adolesc 2011; 40)1): 38-47.

25. Griffiths MD, Meredith A. Video game addiction and its treatment. J Contemp Psychother 2009; 39: 247-253.

26. Grüsser SM, Thalemann R, Griffiths MD. Excessive computer game playing: Evidence for addiction and aggression? Cyberpsychol Behav 2006; 10(2): 290-292.

27. Griffiths MD, Van Rooij AJ, Winther DK, et al. Working towards an international consensus on criteria for assessing Internet gaming disorder: A critical commentary on Petry et al.(2014). Addiction (Abingdon, England) 2016; 111(1): 167.

28. Bozkurt H, Şahin S, Zoroğlu S. İnternet bağımllığı: Güncel bir gözden geçirme. J Contemp Med 2016; 6(2): 113.

29. Kuss DJ, Griffiths MD. Internet gaming addiction: A systematic review of empirical research. Int J Ment Health Addict 2012; 10(2): 278-296.

30. Young KS. Online gaming addiction: Symptoms, risk factors, and treatment. Angela Browne-Miller (Edit). The Praeger International Collection on Addictions. USA: Praeger, 2009: 321-338.

31. Tarhan N, Nurmedov S. Bağımlılık. İstanbul: Timaş Yayınları, 2013.

32. American Psychiatric Association (APA). Diagnostic and Statistical Manual of Mental Disorders (DSM-5). 5th Ed. Washington: American Psychiatric Association, 2013.

33. Şengül C. Büber A. Dijital oyun bağımlıı̆ında tanı ve tedavi. Türk Psikiyatri Derneği Sürekli Eğitim/Sürekli Mesleki Gelişim Dergisi 2016; 6(3): 175-182.

34. World Health Organization (WHO). International Classification of Diseases (ICD-11). Geneva: WHO, 2021.

35. Kuss DJ. Griffiths MD. Online gaming addiction in children and adolescents: A review of empirical research. J Behav Addict 2012; 1(1): 3-22. 
36. Baysak E, Kaya F, Dalgar I. Candansayar S. Online game addiction in a sample from Turkey: Development and validation of the Turkish version of game addiction scale. Klin Psikofarmakol Bulteni 2016; 26(1): 21-31.

37. Yalçın-Irmak A, Erdoğan S. Ergen ve genç erişkinlerde dijital oyun bağımlıı̆̆: Güncel bir bakış. Turk Psikiyatri Derg 2016; 27: 1-11.

38. Kaess M, Durkee T, Brunner, et al. Pathological internet use among European adolescents: Psychopathology and self-destructive behaviours. Eur Child Adolesc Psychiatry 2014; 23(11): 1093-1102.

39. Li H, Wang L, Wang J. The difference of mental health levels and personality traits between internet social addition and internet game addiction in college students. Chinese Journal of Clinical Psychology 2008; 16(4): $413-416$.

40. Yip WS, Kwok YK. Adolescents' Computer Using Phenomena. Hong Kong: Christian Service, 2005.

41. Gentile DA, Choo H, Liau A, et al. Pathological video game use among youths: A two-year longitudinal study. Pediatrics 2001; 127(2): e319-e329.

42. Ferguson CJ, Coulson M, Barnett J. A meta-analysis of pathological gaming prevalence and comorbidity with mental health, academic and social problems. J Psychiatr Res 2011; 45(12): 1573-1578.

43. Rehbein F, Mößle T, Arnaud N, Rumpf HJ. Video game and internet addiction: The current state of research. Nervenarzt 2013; 84: 569-575.

44. Yeşilay. Teknoloji bağımlılığ: Ticari kaygllar çocukları korumanın önüne geçiyor. https://yesilay.org.tr/tr/makaleler/ticari-kaygilar-cocuklari-korumanin-onune-geciyor (Accessed 12.01.2021)

45. Google. Online oyun davranışları. https://www.thinkwithgoogle.com/int/tr-tr/icgoruler/tuketici-trendleri/onlineoyunlar-davranis-trendleri-covid-19/ (Accessed 12.01.2021)

46. UNICEF. Children in a digital world. https://www.unicef.org/media/48601/file (25 Aralık 2020'de ulaşıldı.)

47. Aral N, Doğan-Keskin A. Ebeveyn bakış açısıyla 0-6 yaş döneminde teknolojik alet kullanımının incelenmesi. Addicta 2018; 5(2): 317-348.

48. Griffiths M, Davies M, Chappell D. Breaking the stereotype: The case of online gaming. Cyberpsychol Behav 2003; 6(1): 81-91.

49. Hoeft $F$, Watson $C L$, Kesler SR, et al. Gender differences in the mesocorticolimbic system during computer game-play. J Psychiatr Res 2008; 42(4): 253-258.

50. Gentile D, Lynch P, Linder J, Walsh D. The effects of violent video game habits on adolescent hostility, aggressive behaviors, and school performance. J Adolesc 2004; 27 (1): 5-22.

51. Mcgonigal J. Reality is Broken: Why Games Make Us Better and How They Can Change the World. NY: Penguin Books, 2011.

52. King D, Adair C, Saunders J, Delfabbro P. Clinical predictors of gaming abstinence in help-seeking adult problematic gamers. Psychiatry Res 2018; 261: 581-588.

53. Adanır A, Özatalay E, Doğru H. Oyuna adanmış yaşam: Bir olgu sunumu üzerinden internet oyun oynama bozukluğuna kısa bir bakış. Türkiye Aile Hekimliği Dergisi 2016; 20(2): 85-90.

54. Kırcaburun K, Jonason, PK, Griffiths MD. The dark tetrad traits and problematic online gaming: The mediating role of online gaming motives and moderating role of game types. Pers Individ Dif 2018; 135: 298-303.

55. Gonzalez-Bueso V, Santamaria J, Fernández D, et al. Internet gaming disorder in adolescents: Personality, psychopathology and evaluation of a psychological intervention combined with parent psychoeducation. Front Psychol 2018; 9: e787.

56. Bioulac S, Arfi L, Bouvard M. Attention deficit/hyperactivity disorder and video games: A comparative study of hyperactive and control children. Eur Psychiatry 2008; 23(2): 134-141.

57. King DL, Delfabbro PH. The cognitive psychology of Internet gaming disorder. Clin Psychol Rev 2014; 34(4): 298-308.

58. Popow C, Ohmann S, von Gontard $A$, et al. Computerspielabhängigkeit bei kindern und jugendlichen-ein überblick. Monatsschrift Kinderheillkunde 2019; 167(2): 124-130.

59. Debell M, Chapman C. Computer and Internet Use by Students in 2003. Statistical Analysis Report: National Center for Education Statistics, 2006.

60. Kirsch SJ. Media and Youth: A Developmental Perspective. Hoboken, NJ: Wiley Blackwell, 2010.

61. Avcı K, Avşar Z. Dijital sağlık oyunları. TRT Akademi 2016; 1(2): 472-486.

62. Ocak MA. Eğitsel Dijital Oyunlar. Ankara: Pegem Akademi, 2013.

63. Virtual reality alleviates pain, anxiety for pediatric patients. http://med.stanford.edu/news/allnews/2017/09/virtual-reality-alleviates-pain-anxiety-for-pediatric-patients.html (13 Şubat 2019'da ulaşıldı.)

64. Uslu N, Özkan F. Use of digital games in disease self-management of diabetic children. International Child and Information Safety Congress "Digital Games", 2018. 


\section{Bağımlılık Dergisi - Journal of Dependence}

65. Mustafaoğlu R, Mutlu E, Birinci T, et al. İnternet bağımlıı̆ı ergenlerin öksürük kapasitesini etkiler mi? 11. Ulusal Alkol ve Madde Bağımllığı Kongresi, 2017: 39-40.

66. Zimbardo P, Coulombe ND. Man Disconnected: How Technology Has Sabotaged What It Means to Be Male. (Çev. Tolga Yalur) İstanbul: Pegasus Yayıncılık, 2017.

67. Doğan A. İnternet bağımlıı̆ı yaygınlı̆ı. Yüksek Lisans Tezi, İzmir: Dokuz Eylül Üniversitesi Eğitim Bilimleri Enstitüsü, Aile Eğitimi ve Danışmanlığı ABD, 2013.

68. Van Rooij T, Schoenmakers T, Van Den Eijnden R, et al. Video game addiction and adolescent psychosocial wellbeing: The role of online and real-life friendship quality. Quandt, T., Kröger, S. (Editör) In Multiplayer: The Social Aspects of Digital Gaming. UK: Taylor \& Francis, Routledge, 2013: 215-227.

69. Kim SM, Han DH, Lee YS, et al. Combined cognitive behavioral therapy and bupropion for the treatment of problematic online game play in adolescents with major depressive disorder. Comput Human Behav 2012; 28(5): 1954-1959.

70. Han DH, Hwang JW, Renshaw PF. Bupropion sustained release treatment decreases craving for video games and cue-induced brain activity in patients with Internet video game addiction. Exp Clin Psychopharmacol 2010; 18(4): 297-304.

71. Han DH, Renshaw PF. Bupropion in the treatment of problematic online game play in patients with major depressive disorder. J Psychopharmacol 2012; 26(5): 689-696.

72. Kırcaburun K, Pontes H, Stavropoulos V, et al. Oyun oynama bozukluğu: kısa bir genel bakış. Evren C (Editör). Davranışsal Bağımlııklar Temel Başvuru Kitabı. Ankara: Türkiye Psikiyatri Derneği Yayınları, 2020; 275-285.

73. Torres-Rodríguez A, Griffiths MD, Carbonell X, et al. Treatment efficacy of a specialized psychotherapy program for Internet Gaming Disorder. J Behav Addict 2018; 7(4): 939-952.

74. Torres-Rodríguez A, Griffiths MD, Carbonell X, et al. Internet gaming disorder treatment: A case study evaluation of four different types of adolescent problematic gamers. Int J Ment Health Addict 2019; 17(1): 1-12. 